\title{
High expression of VEGF and PI3K in glioma stem cells provides new criteria for the grading of gliomas
}

\author{
LEI WANG ${ }^{1,2}$, LUYAO ZHANG $^{3}$, WEIGAO SHEN $^{2}$, YANBO LIU $^{4}$ and YINAN LUO ${ }^{1}$ \\ ${ }^{1}$ Department of Neurosurgery, First Clinical Hospital of Norman Bethune Medical School, \\ Jilin University, Changchun, Jilin 130021; ${ }^{2}$ Department of Neurosurgery, The Affiliated Hospital of Beihua University, \\ Jilin, Jilin 132011; ${ }^{3}$ Department of Gastrointestinal Surgery, First Clinical Hospital of Norman Bethune Medical School, \\ Jilin University, Changchun, Jilin 130021; ${ }^{4}$ Department of Pathophysiology, Beihua University, Jilin, Jilin 132013, P.R. China
}

Received October 13, 2014; Accepted September 1, 2015

DOI: $10.3892 / \mathrm{etm} .2015 .2906$

\begin{abstract}
Glioma is a type of tumor derived from glial cells, which is associated with a high level of incidence and mortality. At present, the generation of a fast and efficient method to evaluate the malignancy grade of glioma is required. Cancer stem cells (CSCs) are currently attracting attention in oncological studies; therefore, the present study aimed to investigate novel biomarkers of glioma CSCs, in order to provide new criteria for the grading of glioma. The mRNA expression levels of CD133, (sex determining region Y)-box 2, nestin, vascular endothelial growth factor (VEGF) and phosphoinositide-3-kinase (PI3K) were detected in 15 human samples of high-malignancy glioma and 12 human samples of low-malignancy glioma in vitro. The mRNA expression levels of VEGF and PI3K were higher in the high-malignancy group, as compared with in the low-malignancy group. In conclusion, the mRNA expression levels of VEGF and PI3K in glioma CSCs may be considered a novel criteria for the grading of glioma.
\end{abstract}

\section{Introduction}

Gliomas, which are tumors that originate from neuroglial cells, commonly occur in the brain and occasionally in the spinal cord (1). Gliomas account for $80 \%$ of primary tumors in the brain and central nervous system, and for $30 \%$ of malignant tumors in the brain (2). Patients with low-malignancy gliomas [World Health Organization (WHO) grade II] have good prognoses, with a 10 -year survival rate of up to 47\% (3), and reportedly as long as 17 years (4). By contrast, high-malignancy gliomas (WHO grades III-IV) are rich in vessels and their size increases rapidly. Hypoxic

Correspondence to: Dr Yinan Luo, Department of Neurosurgery, First Clinical Hospital of Norman Bethune Medical School, Jilin University, 71 Xinmin Street, Changchun, Jilin 130021, P.R. China E-mail: yinanluocn@163.com

Key words: glioma, cancer stem cells, disease grading and necrotic tissues in the tumor center can damage the surrounding tissues and destroy the blood-brain barrier; thus, these tumors may relapse even when completely resected. The 1- and 2-year survival rates of high-malignancy gliomas are only 50 and $25 \%$, respectively (5).

Cancer stem cells (CSCs) have the same characteristics as other types of stem cells, but can also differentiate into various types of cells in the tumor tissue $(6,7)$. Thus, CSCs closely affect tumor recurrence and metastasis. Glioma CSCs are important in the development of invasive tumor growth, insensitivity to chemotherapy and radiotherapy, and poor prognosis $(8,9)$. Since glioma CSCs were successfully isolated and cultured in vitro in 2004 (10), their characteristics have been studied extensively. Currently known glioma CSC markers include CD133, nestin, (sex determining region Y)-box 2 (SOX2), ATP-binding cassette sub-family G member 2 (ABCG2) and musashi-1 (11-15), with CD133 considered to be the most important of these markers. CD133 ${ }^{+}$glioma CSCs form cell spheres in culture medium that contains growth factors (16), and differentiate into neurons and glial cells following the removal of the growth factors (17-19). However, certain $\mathrm{CD} 33^{-}$glioma cells also exhibit similar characteristics to CSCs (20). In addition, certain types of cells, such as endothelial cells, are also $\mathrm{CD}_{133^{+}}(21)$. Therefore, CD133, even alongside other biomarkers, may not be a specific biomarker for glioma CSCs.

Vascular endothelial growth factor (VEGF) is highly expressed in glioma cells (22-24), and its expression is directly associated with the malignancy and prognosis of gliomas (25). Phosphoinositide-3-kinase (PI3K) is a lipid second messenger associated with intracellular signal transduction that can catalyze the formation of phosphoinositide- 3 phosphate, which is the phosphorylated product of the third hydroxyl of inositol phosphate (26). PI-3,4,5- $\mathrm{P}_{3}$ is the phosphorylated product of PI3K, which is gathered in the inner surface of the cell membrane. Protein kinase B (Akt) combines with PI-3,4,5- $\mathrm{P}_{3}$ and is subsequently activated. The activated Akt then enters the cell membrane, where it is phosphorylated by PDK1 and PDK2, and regulates a series of functions, including the cell cycle, growth and survival (27). PI3K comprises of five subtypes, including $\mathrm{p} 55 \alpha, \mathrm{p} 55 \gamma, \mathrm{p} 85 \alpha, \mathrm{p} 85 \beta$ and $\mathrm{p} 50 \alpha$, all of which are expressed in neuronal cells in the rat brain, 
indicating that $\mathrm{PI} 3 \mathrm{~K}$ is important in signal transduction in the brain (28). However, the association between PI3K/Akt gene expression and glioma remains unclear.

In the present study, specimens from glioma patients were divided into the following two groups according to clinical grading: Low-malignancy (WHO grade II) and high-malignancy (WHO grades III-IV) groups (29). Stem cells were extracted from fresh tumor tissues, and the expression levels of CD133, nestin, SOX2, VEGF and PI3K were detected by reverse transcription-quantitative polymerase chair reaction (RT-qPCR), in order to identify the association of glioma CSCs with the VEGF and PI3K signal transduction systems. To the best of our knowledge, this is the first study investigating the expression levels of VEGF and PI3K in glioma CSCs obtained from glioma patients. The results will provide first-hand information for further study of drugs that target glioma.

\section{Materials and methods}

Sample collection. Samples were collected in strict accordance with the scientific research sample collection guidelines of the Department of Neurosurgery the Affiliated Hospital of Beihua University (Jilin, Jilin). Glioma samples were successfully collected from 27 patients with glioma who were undergoing resection surgery at the Department of Neurosurgery, between 2010 and 2013. Tissue samples were diagnosed by pathological section and classified into 12 low- and 15 high-malignancy gliomas, according to the WHO guidelines (29-33). The tissue samples immediately underwent tissue digestion and cell isolation. This study was conducted in accordance with the declaration of Helsinki and was approved by the Ethics Committee of Jilin University (Changchun, China). Written informed consent was obtained from all the participants.

Isolation and purification of glioma CSCs. Several 6-well plates were coated with $20 \mu \mathrm{g} / \mathrm{ml}$ poly-ornithine (Sigma-Aldrich, Carlsbad, CA, USA) and incubated in a cell incubator at $37^{\circ} \mathrm{C}$ for at least $2 \mathrm{~h}$. Subsequently, the poly-ornithine was removed by washing once with deionized water, the plates were rinsed once with phosphate-buffered saline (PBS), and were then incubated with a final concentration of $5 \mu \mathrm{g} / \mathrm{ml}$ laminine (Sigma-Aldrich) for $1 \mathrm{~h}$.

Fresh glioma tumor tissues were cut into small sections (7 $\mu \mathrm{m})$ and rinsed twice with Hank's balanced salt solution (HBSS; Gibco Life Technologies, Grand Island, NY, USA) containing 20\% fetal bovine serum (FBS; Thermo Fisher Scientific, Inc., Pittsburgh, PA, USA). The specimens were then rinsed three times with HBSS without FBS in order to remove blood cells and then digested with $0.25 \%$ trypsin (Gibco Life Technologies) at $37^{\circ} \mathrm{C}$ for $10 \mathrm{~min}$. Subsequently, the digestion was terminated using $3 \mathrm{ml}$ HBSS containing $20 \% \mathrm{FBS}$, and the samples were centrifuged at $400 \mathrm{x}$ g at $4^{\circ} \mathrm{C}$ for $3 \mathrm{~min}$. The supernatant was then discarded, and the cells were resuspended using the neural stem cell culture medium (Thermo Fisher Scientific, Inc., Waltham, MA, USA). The cell suspension was filtered through a $70-\mu$ m nylon mesh (Mumford Industries, Inc., CA, USA) and the cells were transferred to the 6-well plates that had been prepared previously. To further evaulate biomarker expression, U251 human glioma cells (Sigma-Aldrich) were used as a control. The U251 and primary neural stem cells were cultured in medium containing $10 \% \mathrm{FBS}, 40 \mathrm{ng} / \mathrm{ml}$ fibroblast growth factor 2, $20 \mathrm{ng} / \mathrm{ml}$ epidermal growth factor (EGF) and $20 \mathrm{ng} / \mathrm{ml}$ platelet-derived growth factor (all from Gibco Life Technologies) on the first day. On the second day, the medium was replaced with fresh medium without FBS, and thereafter, half the medium was changed every day, with the addition of fresh growth factors. The cells were observed and images were captured under 200x magnification using a microscope (BX51-32H01; Olympus Corporation, Tokyo, Japan).

Detection of glioma CSCs using RT-qPCR. The total RNA of glioma CSCs and U251 cells was extracted using an RNeasy kit (Qiagen, Hilden, Germany). Next, $1 \mu \mathrm{g}$ total RNA was reverse transcribed into cDNA using iScript cDNA Synthesis kit (Bio-Rad Laboratories, Inc., Hercules, CA, USA), and PCR was performed using PCR Master Mix (Applied Biosystems, Life Technologies, Rockville, MD, USA). The PCR protocol comprised of initial denaturation at $95^{\circ} \mathrm{C}$ for $10 \mathrm{~min}, 35$ cycles at $95^{\circ} \mathrm{C}$ for $30 \mathrm{sec}, 54^{\circ} \mathrm{C}$ for $30 \mathrm{sec}$ and $72^{\circ} \mathrm{C}$ for $30 \mathrm{sec}$, and then extension at $72^{\circ} \mathrm{C}$ for $10 \mathrm{~min}$. The primers used in the present study are listed in Table I. PCR products were seperated by $1 \%$ agarose gel electrophoresis, and results were quantified using model-driven agility software (Kepler 4.3; Eclipse Foundation, Inc., Ottawa, ON, Canada).

Statistical analysis. VEGF and PI3K mRNA expression levels were normalized to GAPDH. Student's t-test was used to analyze the VEGF and PI3K expression levels between the two glioma groups. All analyses were conduced using SPSS 20 software (IBM SPSS, Armonk, NY, USA). P<0.05 was considered to indicate a statistically significance difference.

\section{Results}

Comparison of clinical conditions. All the glioma patients included in the present study had not received any treatment prior to surgery. The patients were divided into the low-malignancy (WHO grade II; n=12) and high-malignancy groups (WHO grades III-IV; $n=15$ ). No statistically significant differences in the gender, age, tumor site or pathological type were observed between the two groups ( $\mathrm{P}>0.05$; Table II).

Morphology of glioma CSCs. Glioma CSCs were observed in the suspended and adherent state (Fig. 1). These two cell states display different shapes. The suspended cells formed spheres, whereas the adherent cells exhibited a spindle shape. Notably, the amount of sphere-shaped CSCs was increased in the highmalignancy group, as compared with in the low malignancy group. Taken together, various states of CSCs were detected in the cell culture.

Identification of glioma stem cell markers. To validate the expression levels of conventional CSC biomarkers, the mRNA expression levels of CD133, SOX2 and nestin were detected in the high- and low-malignancy glioma CSCs. CD133 expression levels were markedly lower in the low-malignancy group, as compared with in the high-malignancy group; however, there was no significant difference with the U251 cells (Fig. 2). 
Table I. Primers used in the present study.

\begin{tabular}{lll}
\hline Gene & Forward primer $\left(5^{\prime} \rightarrow 3^{\prime}\right)$ & Reverse primer $\left(5^{\prime} \rightarrow 3^{\prime}\right)$ \\
\hline CD133 & acactgctggtgtgctgac & cccaaggaccacttcacagt \\
SOX2 & cacaactcggagatcagcaa & ctccgggaagcgtgtactta \\
Nestin & aggctgagaactctcgcttg & attaggcaagggggaagaga \\
VEGF & cacgaacgagtccctagagc & atggtgatgcggttttcttc \\
PI3K & attacgctagttacactgca & tggacctggccatcgactga \\
GAPDH & accacagtccatgccatcac & tccaccacctgttgctgta \\
\hline
\end{tabular}

SOX2, (sex determining region Y)-box 2 (SOX2); VEGF, vascular endothelial growth factor; PI3K, phosphoinositide-3-kinase.

Table II. Comparison of clinical characteristics of patients with glioma.

Characteristic

Mean age, years

Age range, years

Male : female ratio

Tumor site

Frontal lobe

Temporal lobe

Parietal lobe

Pathological type

Glioblastoma

Oligodendroglioma

Diffuse astroglioma
Low-malignancy group $(\mathrm{n}=12)$

High-malignancy group $(\mathrm{n}=15)$

$\begin{array}{cc}42 & 45 \\ 33-52 & 28-56 \\ 1.8: 1 & 1.6: 1\end{array}$

5

4

3

5

2

5
6

4

$1.6: 1$

4

4

7

Patients were divide into the low-malignancy (WHO grade II; n=12) and high-malignancy groups (WHO grades III-IV; $\mathrm{n=15}$ ). No statistically significant differences between the two groups were observed in the gender, age, tumor site or pathological type $(\mathrm{P}>0.05)$.

$\mathbf{A}$

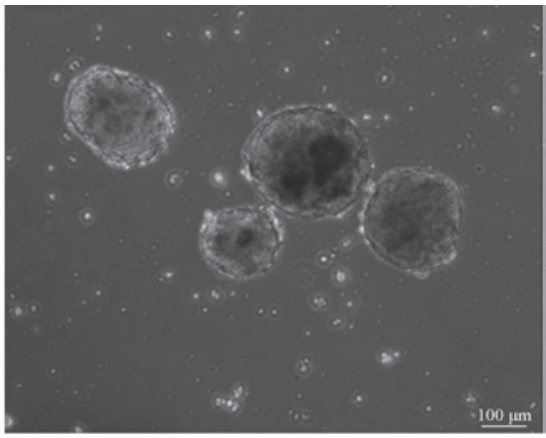

$\mathbf{B}$

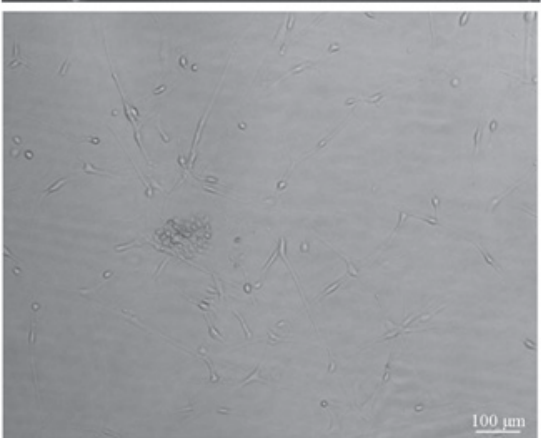

Figure 1. Morphology of glioma stem cells. (A) Glioma CSCs formed spheres in the suspended state, (B) whereas the appearance of cells in the adherent state was similar to that of neural stem cells. Bar, $100 \mu \mathrm{m}$. CSCs, cancer stem cells.

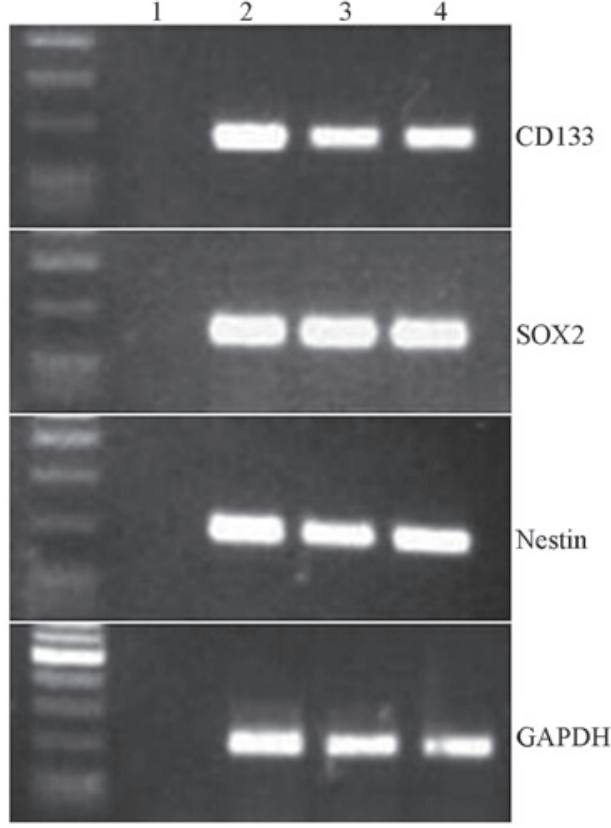

Figure 2. Gene expression levels for CD133, SOX2 and nestin in glioma cancer stem cells (CSCs). Levels were similar to those in CSCs extracted from U851 glioma cells. Lane 1, negative control; lanes 2 and 3, two glioma CSC samples; lane 4, U251 cell line. SOX2, (sex determining region Y)-box 2. 
Table III. Differential expression of VEGF and PI3K in the low- and high-malignancy glioma CSCs.

A, Low-malignancy glioma CSCs $(n=12)$

\begin{tabular}{lrr}
\hline Patient & VEGF levels & PI3K levels \\
\hline 1 & $14.5 \pm 1.0$ & $4.6 \pm 0.2$ \\
2 & $10.9 \pm 0.6$ & $6.4 \pm 0.1$ \\
3 & $5.0 \pm 0.2$ & $2.6 \pm 0.6$ \\
4 & $4.7 \pm 0.5$ & $5.8 \pm 0.7$ \\
5 & $13.2 \pm 2.0$ & $6.8 \pm 0.6$ \\
6 & $9.5 \pm 1.5$ & $1.7 \pm 0.1$ \\
7 & $11.7 \pm 1.2$ & $1.0 \pm 0.1$ \\
8 & $7.8 \pm 0.4$ & $3.6 \pm 0.2$ \\
9 & $12.6 \pm 1.7$ & $2.4 \pm 0.1$ \\
10 & $10.3 \pm 1.6$ & $4.7 \pm 0.3$ \\
11 & $6.9 \pm 0.3$ & $2.4 \pm 0.7$ \\
12 & $7.2 \pm 0.3$ & $4.2 \pm 0.8$ \\
\hline
\end{tabular}

B, High-malignancy glioma CSCs $(n=15)$

\begin{tabular}{lrr}
\hline Patient & VEGF levels & PI3K levels \\
\hline 1 & $28.4 \pm 2.5$ & $15.7 \pm 0.9$ \\
2 & $18.9 \pm 1.7$ & $18.5 \pm 1.2$ \\
3 & $37.9 \pm 2.6$ & $25.8 \pm 2.7$ \\
4 & $15.4 \pm 1.2$ & $28.4 \pm 3.0$ \\
5 & $19.5 \pm 1.3$ & $8.5 \pm 0.5$ \\
6 & $32.5 \pm 2.0$ & $26.8 \pm 0.4$ \\
7 & $45.2 \pm 2.4$ & $9.8 \pm 0.5$ \\
8 & $26.3 \pm 2.9$ & $20.0 \pm 2.1$ \\
9 & $35.8 \pm 2.4$ & $15.8 \pm 1.9$ \\
10 & $24.7 \pm 1.3$ & $13.8 \pm 1.4$ \\
11 & $38.9 \pm 2.1$ & $23.3 \pm 1.8$ \\
12 & $19.9 \pm 1.2$ & $24.8 \pm 2.1$ \\
13 & $32.4 \pm 2.3$ & $28.4 \pm 1.9$ \\
14 & $15.3 \pm 0.5$ & $23.0 \pm 1.2$ \\
15 & $23.6 \pm 1.6$ & $17.2 \pm 2.1$ \\
\hline
\end{tabular}

Data are presented as the mean \pm standard deviation. VEGF, vascular endothelial growth factor; PI3K, phosphoinositide-3-kinase; CSCs, cancer stem cells.

Furthermore, neither SOX2 nor nestin expression levels differed between the glioma CSCs and U251 cells. These results suggest that the transcriptional levels of CD133, SOX2 and nestin may not be able to efficiently evaluate the malignant stage of glioma CSCs.

Expression levels of VEGF and PI3K. The present study further investigated the VEGF and PI3K mRNA expression levels between the two glioma groups. VEGF was significantly upregulated in the high-malignancy group, as compared with the low-malignancy group $(\mathrm{T}$ value $=12.655, \mathrm{P}=0.002$ ). In addition, the mRNA expression levels of PI3K exhibited a similar
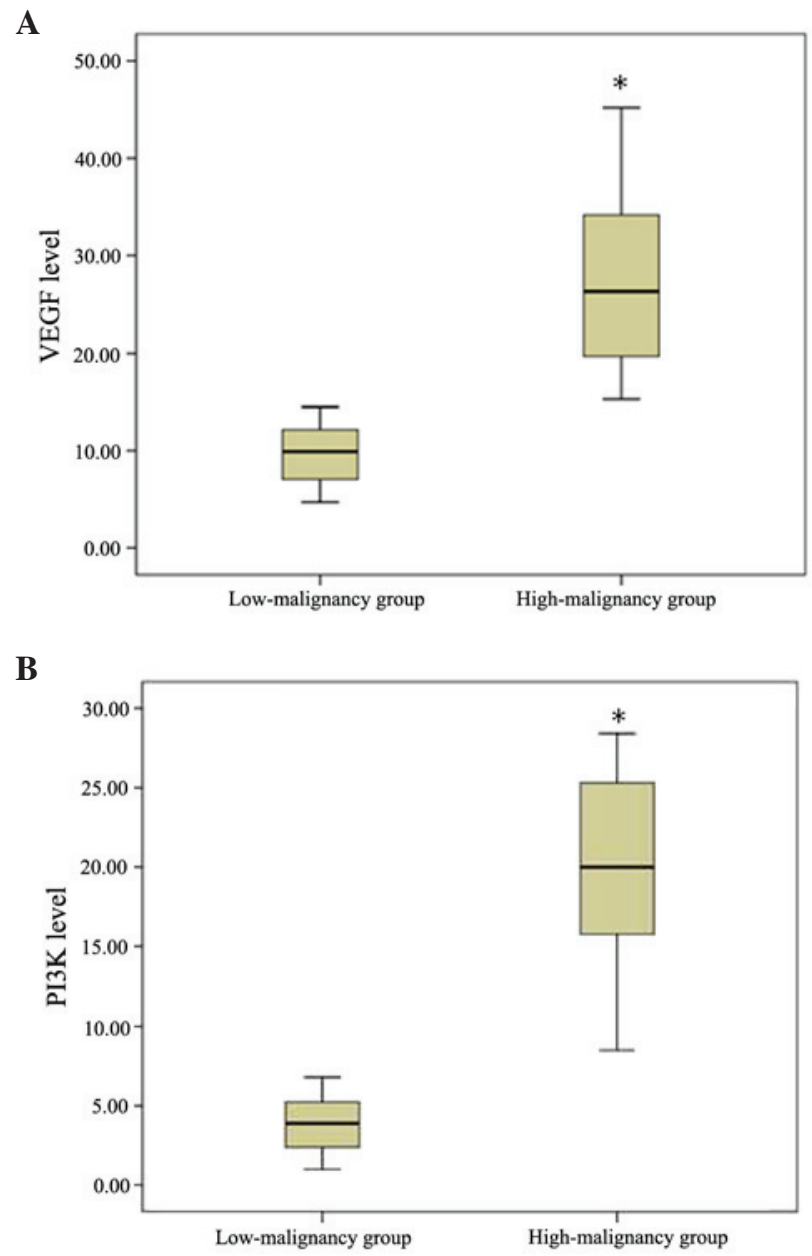

Figure 3. Comparison of expression levels of (A) VEGF and (B) PI3K in the low- and high-malignancy groups. Compared with the low-malignancy group, the expression levels of VEGF and PI3K were significantly higher in the high-malignancy group $\left({ }^{*} \mathrm{P}=0.001\right)$. VEGF, vascular endothelial growth factor; PI3K, phosphoinositide-3-kinase.

tendency ( $\mathrm{T}$ value $=15.948, \mathrm{P}=0.001$ ) (Table III; Fig. 3A and B). These results suggest that the transcriptional levels of VEGF and PI3K may significantly differ in the various malignant stages of glioma.

\section{Discussion}

The incidence of glioma is 3.8/100,000 for men and 3.1/100,000 for women in developing countries, and 5.8/100,000 for men and 4.4/100,000 for women in developed countries (34). In the United States, malignant glioma accounts for $70 \%$ of newly-diagnosed cases of glioma, of which glioblastoma accounts for $60-70 \%(35,36)$. The glioma classification system of the World Health Organization (WHO) includes four grades, based on the pathological atypia, mitotic condition and anaplasia. The present study aimed to detect the differences in the transcriptional expression of CD133, SOX2, nestin, VEGF and PI3K between high-malignancy and low-malignancy glioma CSCs. The results of the present study suggested a robust association among tumor grade, invasion of CSCs and prognosis. In addition, the expression levels of VEGF and PI3K in WHO grade III-IV samples were found to be significantly 
higher compared with those in grade II samples, which implies that the expression levels of these two biomarkers may be used as criteria for the clinical grading of gliomas. However, a larger-scale study is required to further confirm this finding.

Mutation in the isocitrate dehydrogenase (IDH) gene is widely detected in low-grade gliomas and is generally considered to be an important predictor of prognosis in glioma patients $(37,38)$. The IDH mutation may induce abnormal formation of 2-hydroxyglutarate, which inhibits ketoglutarate-dependent dioxygenase, resulting in abnormal histone and DNA methylation, and thus to poor prognosis for glioma patients $(38,39)$.

Methylation of the $\mathrm{O}^{6}$-alkylguanine DNA alkyltransferase (MGMT) gene promoter is also associated with glioma prognosis (40). Hegi et al confirmed that MGMT gene promoter methylation was associated with long-term survival in glioma patients who received only chemotherapy treatment (41). Furthermore, Brandes et al revealed that MGMT gene demethylation increased the vascular permeability of glioblastomas (42). MGMT promoter demethylation plays different roles in gliomas of different grades and pathological types. For instance, the types of gene mutations in WHO grade IV gliomas differ from those in other grades of glioma. Mutations of the IDH and p53 genes are rare, whereas the mutation of EGF receptor (EGFR) is common (43). Further experiments with larger-scale samples are required to detect the significance of mutations in the IDH, MGMT, EGFR and p53 genes.

CSCs not only have the same characteristics as other types of stem cells, but can also differentiate into various types of cells in tumor tissue, and greatly affect tumor recurrence and metastasis. Since Bonnet and Dick isolated leukemia stem cells in 1997 (44), researchers have identified CSCs in specimens of brain, lung, colon, ovary, pancreas and prostate cancer (45-50). Neurosphere assay is a primary in vitro method for the culture of neural stem cells, which can then differentiate into neurons and glial cells (51-53). Neural stem cells are gathered to form neurospheres subsequent to cell division, and the size of neurospheres increases along with the increase of cell division times, so as to achieve a rise in the number of cells. Since glioma CSCs were first isolated and successfully cultured in vitro in 2004 (10), thorough research has been conducted on these cells. Glioma CSCs have been found to express CD133, SOX2, nestin and other markers. However, the role of glioma CSCs in tumor grading has not received considerable attention.

In conclusion, the results of the present study revealed that the expression levels of VEGF and PI3K mRNA in glioma CSCs from patients with grade III-IV glioma were significantly higher compared with those in glioma CSCs of patients with grade II disease. Thus, the expression of VEGF and PI3K mRNA in glioma stem cells may play a key role in the clinical grading of glioma and the accurate prediction of the disease prognosis.

\section{References}

1. Mamelak AN and Jacoby DB: Targeted delivery of antitumoral therapy to glioma and other malignancies with synthetic chlorotoxin (TM-601). Expert Opin Drug Deliv 4: 175-186, 2007.

2. Goodenberger ML and Jenkins RB: Genetics of adult glioma. Cancer Genet 205: 613-621, 2012.
3. Smoll NR, Gautschi OP, Schatlo B, Schaller K and Weber DC: Relative survival of patients with supratentorial low-grade gliomas. Neuro Oncol 14: 1062-1069, 2012.

4. Olson JD, Riedel E and DeAngelis LM: Long-term outcome of low-grade oligodendroglioma and mixed glioma. Neurology 54: 1442-1448, 2000.

5. Ohgaki H and Kleihues P: Population-based studies on incidence, survival rates and genetic alterations in astrocytic and oligodendroglial glioma. J Neuropathol Exp Neurol 64: 479-489, 2005.

6. Plaks V, Kong N and Werb Z: The cancer stem cells niche: How essential is the niche in regulating stemness of tumor cells? Cell Stem Cell 16: 225-238, 2015.

7. Wang L, Xue Y, Shen Y, Li W, Cheng Y, Yan X, Shi W, Wang J, Gong Z, Yang G, et al: Claudin 6: A novel surface marker for characterizing mouse pluripotent stem cells. Cell Res 22: 1082-1085, 2012.

8. Gilbertson RJ and Rich JN: Making a tumour's bed: Glioblastoma stem cells and the vascular niche. Nat Rev Cancer 7: 733-736, 2007.

9. Chen L, Chen XR, Chen FF, Liu Y, Li P, Zhang R, Yan K, Yi YJ, Xu ZM and Jiang XD: MicroRNA-107 inhibits U87 glioma stem cells growth and invasion. Cell Mol Neurobiol 33: 651-657, 2013.

10. Galli R, Binda E, Orfanelli U, Cipelletti B, Gritti A, De Vitis S, Fiocco R, Foroni C, Dimeco F and Vescovi A: Isolation and characterization of tumorigenic, stem-like neural precursors from human glioblastoma. Cancer Res 64: 7011-7021, 2004.

11. Gaedicke S, Braun F, Prasad S, Machein M, Firat E, Hettich M, Gudihal R, Zhu X, Klingner K, Schüler J, et al: Noninvasive positron emission tomography and fluorescence imaging of CD133+ tumor stem cells. Proc Natl Acad Sci USA 111: E692-E701, 2014.

12. Lubanska D, Market-Velker BA, deCarvalho AC, Mikkelsen T, Fidalgo da Silva E and Porter LA: The cyclin-like protein Spy1 regualtes growth and division characteristics of the $\mathrm{CD} 133^{+}$ population in human glioma. Cancer Cell 25: 64-76, 2014.

13. Jin X, Jin X, Jung JE, Beck S and Kim H: Cell surface nestin is a biomarker for glioma stem cells. Biochem Biophys Res Commun 433: 496-501, 2013.

14. Dell'Albani P: Stem cell markers in gliomas. Neurochem Res 33: 2407-2415, 2008

15. Strojnik T, Røsland GV, Sakariassen PO, Kavalar R and Lah T: Neural stem cell markers, nestin and musashi proteins, in the progrssion of human glioma: Correlation of nestin with prognosis of patient survival. Surg Neurol 68: 133-143, 2007.

16. Raso A, Negri F, Gregorio A, Nozza P, Mascelli S, De Marco P, Merello E, Milanaccio C, Ravegnani M, Cama A, et al: Successful isolation and long-term establishment of a cell line with stem cell-like features from an anaplastic medulloblastoma. Neuropathol Appl Neurobiol 34: 306-315, 2008.

17. Hemmati HD, Nakano I, Lazareff JA, Masterman-Smith M, Geschwind DH, Bronner-Fraser M and Kornblum HI: Cancerous stem cells can arise from pediatric brain tumors. Proc Natl Acad Sci USA 100: 15178-15183, 2003.

18. Ignatova TN, Kukekov VG, Laywell ED, Suslov ON, Vrionis FD and Steindler DA: Human cortical glial tumors contain neural stem-like cells expressing astroglial and neuronal markers in vitro. Glia 39: 193-206, 2002.

19. Dolgova EV, Alyamkina EA, Efremov YR, Nikolin VP, Popova NA, Tyrinova TV, Kozel AV, Minkevich AM, Andrushkevich OM, Zavyalov EL, et al: Identification of cancer stem cells and a strategy for their elimination. Cancer Biol Ther 15: 1378-1394, 2014.

20. Beier D, Hau P, Proescholdt M, Lohmeier A, Wischhusen J, Oefner PJ, Aigner L, Brawanski A, Bogdahn U and Beier CP: CD133(+) and CD133(-) glioblastoma-derived cancer stem cells show differential growth characteristics and molecular profiles. Cancer Res 67: 4010-4015, 2007.

21. Bao S, Wu Q, McLendon RE, Hao Y, Shi Q, Hjelmeland AB, Dewhirst MW, Bigner DD and Rich JN: Glioma stem cells promote radioresistance by preferential activation of the DNA damage response. Nature 444: 756-760, 2006.

22. Ma C, Li Y, Zhang X, Zhao G and Xu H: Levels of vascular endothelial growth factor and matrix metalloproteinase-9 proteins in patients with glioma. J Int Med Res 42: 198-204, 2014.

23. Li Q, Qiao G, Ma J and Li Y: Downregulation of VEGF expression attenuates maligant biological behavior of C6 glioma stem cells. Int J Oncol 44: 1581-1588, 2014.

24. Plate KH, Breier G, Millauer B, Ullrich A and Risau W: Up-regulation of vascular endothelial growth factor and its cognate receptors in a rat glioma model of tumor angiogenesis. Cancer Res 53: 5822-5827, 1993. 
25. Das $\mathrm{S}$ and Marsden PA: Angiogenesis in glioblastoma. N Engl J Med 369: 1561-1563, 2013.

26. Whitman M, Downes CP, Keeler M, Keller T and Cantley L: Type I phosphatidylinositol kinase makes a novel inositol phospholipid, phosphatidylinositol-3-phosphate. Nature 332: 644-646, 1988.

27. Fresno Vara JA, Casado E, de Castro J, Cejas P, Belda-Iniesta C and González-Barón M: PI3K/Akt signaling pathway and cancer. Cancer Treat Rev 30: 193-204, 2004.

28. Shin BC, Suzuki M, Inukai K, Anai M, Asano T and Takata K: Multiple isoforms of the regulatory subunit for phosphatidylinositol 3 kinase (PI3-kinase) are expressed in neurons in the rat brain. Biochem Biophys Res Commun 246: 313-319, 1998.

29. Weller M, Weber RG, Willscher E: Molecular classification of diffuse cerebral WHO grade II/III gliomas using genomeand transcriptome-wide profiling improves stratification of prognostically distinct patient groups. Acta Neuropathol 129: 679-693, 2015.

30. Simonetti G, Gaviani P, Botturi A, Innocenti A, Lamperti E and Silvani A: Clinical management of grade III oligodendroglioma. Cancer Manag Res 7: 213-223, 2015.

31. Zhang C, Bao Z, Zhang W and Jiang T: Progress on molecular biomarkers and classification of malignant gliomas. Front Med 7: 150-156, 2013.

32. Kahramancetin $\mathrm{N}$ and Tihan T: Aggressive behavior and anaplasia in pleomorphic xanthoastrocytoma a plea for a revision of the current WHO classification. CNS Oncol 2: 523-530, 2013

33. Schafer ML, Maurer MH, Synowitz M, Wustefeld J, Marnitz T, Streitparth F and Wiener E: Low- (WHO II) and anaplastic (WHO III) gliomas: Differences in morphology and MRI signal intensities. Eur Radiol 23: 2846-2853, 2013.

34. Ferlay J, Shin HR, Bray F, Forman D, Mathers C and Parkin DM: Estimates of worldwide burden of cancer in 2008: GLOBOCAN 2008. Int J Cancer 127: 2893-2917, 2010.

35. Louis DN, Ohgaki H, Wiestler OD, Cavenee WK, Burger PC, Jouvet A, Scheithauer BW and Kleihues P: The 2007 WHO classification of tumours of the central nervous system. Acta Neurophthol 114: 97-109, 2007.

36. Ostrom QT, Gittleman H, Farah P, Ondracek A, Chen Y, Wolinsky Y, Stroup NE, Kruchko C and Barnholtz-Sloan JS: CBTRUS statistical report: Primary brain and central nervous system tumors diagnosed in the United States in 2006-2010. Neuro Oncol 15 Suppl 2: ii1-ii56, 2013.

37. Olar A and Aldape KD: Biomarkers classification and therapeutic decision-making for malignant gliomas. Curr Treat Options Oncol 13: 417-436, 2012.

38. Ichimura K: Molecular pathogenesis of IDH mutations in gliomas. Brain Tumor Pathol 29: 131-139, 2012.
39. Birner P, Pusch S, Christov C, Mihaylova S Toumangelova-Uzeir K, Natchev S, Schoppmann SF, Tchorbanov A, Streubel B, Tuettenberg J and Guentchev M: Mutant IDH1 inhibits PI3K/Akt signaling in human glioma. Cancer 120: 2440-2447, 2014.

40. Olson RA, Brastianos PK and Palma DA: Prognostic and predictive value of epigenetic silencing of MGMT in patients with high grade gliomas: A systematic review and meta-analysis. J Neuroncol 105: 325-335, 2011.

41. Hegi ME, Diserens AC, Gorlia T, Hamou MF, de Tribolet N, Weller M, Kros JM, Hainfellner JA, Mason W, Mariani L, et al: MGMT gene silencing and benefit from temozolomide in glioblastoma. N Eng J Med 352: 997-1003, 2005.

42. Brandes AA, Franceschi E, Tosoni A, Blatt V, Pession A, Tallini G, Bertorelle R, Bartolini S, Calbucci F, Andreoli A, et al: MGMT promoter methylation status can predict the incidence and outcome of pseudoprogression after concomitant radiochemotherapy in newly diagnosed glioblastoma patients. J Clin Oncol 26: 2192-2197, 2008.

43. Ohgaki $\mathrm{H}$ and Kleihues P: Genetic pathways to primary and secondary glioblastoma. Am J Pathol 170: 1445-1453, 2007.

44. Bonnet D and Dick JE: Human acute myeloid leukemia is organized as a hierarchy that originates from a primitive hematopoietic cell. Nat Med 3: 730-737, 1997.

45. Singh SK, Clarke ID, Terasaki M, Bonn VE, Hawkins C, Squire J and Dirks PB: Identification of a cancer stem cell in human brain tumors. Cancer Res 63: 5821-5828, 2003.

46. Al-Hajj M, Wicha MS, Benito-Hernandez A, Morrison SJ and Clarke MF: Prospective identification of tumorigenic breast cancer cells. Proc Natl Acad Sci USA 100: 3983-3988, 2003.

47. O'Brien CA, Pollett A, Gallinger S and Dick JE: A human colon cancer cell capable of initiating tumor growth in immunodeficient mice. Nature 445: 106-110, 2007.

48. Zhang S, Balch C, Chan MW, Lai HC, Matei D, Schilder JM, Yan PS, Huang TH and Nephew KP: Identification and characterization of ovarian cancer-initiating cells from primary human tumors. Cancer Res 68: 4311-4320, 2008

49. Li C, Heidt DG, Dalerba P, Burant CF, Zhang L, Adsay V, Wicha M, Clarke MF and Simeone DM: Identification of pancreatic cancer stem cells. Cancer Res 67: 1030-1037, 2007.

50. Maitland NJ and Collins AT: Prostate cancer stem cells: A new target for therapy. J Clin Oncol 26: 2862-2870, 2008.

51. Temple S: Division and differentiation of isolated CNS blast cells in microculture. Nature 340: 471-473, 1989.

52. ReynoldsBA, Tetzlass W and Weiss S: A MultipotentEGF-responsive striatal embryonic progenitor cell produces neurons and astrocytes. J Neurosci 12: 4564-4574, 1992.

53. Reynolds BA and Weiss A: Generation of neurons and astrocytes from isolated cells of the adult mammalian central nervous system. Science 255: 1707-1710, 1992. 